\title{
ANALISIS PELESTARIAN SITUS CAGAR BUDAYA SEKARAN (STUDI KASUS SITUS SEKARAN DI DESA SEKARPURO KABUPATEN MALANG)
}

\author{
Wahyu Nurvita Afnani ${ }^{{ }^{*}}$, Neni Wahyuningtyas ${ }^{1}$, Bayu Kurniawan ${ }^{1}$ \\ ${ }^{1}$ Universitas Negeri Malang, Indonesia \\ *e-mail: wahyu.nurvita.1707416@students.um.ac.id
}

\begin{abstract}
Abstrak
Penelitian ini bertujuan untuk menganalisis pelestarian Situs Cagar Budaya Sekaran di Desa Sekarpuro, Kecamatan Pakis, Kabupaten Malang. Penelitian ini menggunakan rancangan penelitian kualitatif dengan jenis penelitian deskriptif. Sumber data yang digunakan adalah sumber data primer dan sumber data sekunder. Teknik pengumpulan data dalam penelitian ada tiga, yaitu wawancara, observasi, dan dokumentasi. Hasil penelitian ini menunjukan bahwa Situs Sekaran ditemukan pada tahun 2019 saat penggalian tanah yang dilakukan oleh pekerja proyek tol Malang-Pandaan. Sebelumnya masyarakat Desa Sekapuro sudah lama mengenal daerah tersebut sebagai bangunan bata kuno, namun tidak pernah dilaporkan karena rendahnya kesadaran sejarah masyarakat Desa Sekarpuro. Peran pemerintah desa dalam melindungi Situs Sekaran meliputi perawatan, perlindungan dan pengawasan. Peran arkeolog, sejarawan, BPCB (Balai Pelestarian Cagar Budaya) dan komunitas peduli sejarah dalam pelestarian Situs Sekaran meliputi penyelamatan sejak ditemukannya situs tersebut, pemugaran, mendorong penelitian dan menetapkannya sebagai Cagar Budaya menurut wilayah administratifnya.
\end{abstract}

Kata kunci: Pelestarian Cagar Budaya; Situs Sekaran; Situs Sejarah

\begin{abstract}
This research aims to analyze the preservation of Sekaran Cultural Heritage Site's in Sekarpuro Village, Pakis Subdistrict, Malang Regency. This study used a qualitative research design with a descriptive research type. Sources of data used are primary data sources and secondary data sources. There are three data collection techniques in the study, namely interviews, observation, and documentation. This study indicates that the Sekaran Site was discovered in 2019 when land excavation was carried out by workers of the Malang-Pandaan toll road project. Previously, the people of Sekapuro Village had long known the area as an ancient brick building. However, it was never reported due to the low historical awareness of the Sekarpuro Village community. The role of the village government in protecting the Sekaran Site includes maintenance, protection, and supervision. The roles of an archaeologist, historians, Cultural Heritage Preservation Center, and community that cares about history in preserving Sekaran Site, including rescue started from the site's discovery, restoration, encourage research and designate it as a Cultural Heritage according to its administrative area.
\end{abstract}

Keywords: Cultural Heritage Preservation; Sekaran Site; Historical Site

This is an open access article under the CC BY-SA license.

Copyright (C 2021 by Author. Published by Universitas Pendidikan Ganesha.

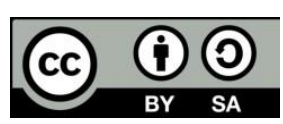

Doi: http://dx.doi.org/10.23887/jish-undiksha.v10i3.34307 Jurnal IImu Sosial dan Humaniora | 391 


\section{PENDAHULUAN}

Kabupaten Malang memiliki potensi kesejarahan yang sangat besar. Potensi kesejarahan ini dapat dibuktikan dengan banyaknya peninggalan kebudayaan pada masa kuno. Berdasarkan persebarannya terdapat beberapa situs sejarah yang ditemukan di Kabupaten Malang diantaranya adalah Situs Candi Jago, Situs Sumberawan, Situs Candi Kidal (Afida, et al., 2014; Ramli \& Wikantiyoso, 2018; Turaeni, 2014), Situs Candi Badut, Situs Songgoriti, dan Situs Candi Singosari (Kencana \& Basid, 2018; Handoko, 2018; Zahroh, 2014). Kemudian juga terdapat Situs Patirtan diantaranya adalah Situs Patirtan Candi Sumberawan, Situs Sumber Polaman, Situs Ken Dedes Watu Gede, Situs Sendang Widodaren, Situs Pura Patirtan Taman Pasupati, dan Situs Purbakala Ngawonggo (Sulistyo, et al., 2020).

Situs sejarah di Kabupaten Malang bisa saja bertambah seiring dengan kegiatan yang dilakukan oleh manusia dalam pembangunan. Penemuan-penemuan situs sejarah berdasarkan kegiatan manusia dalam pembangunan, misalnya Situs Kuno yang berada di Desa Ngenep, Kecamatan Karangploso, Kabupaten Malang. Situs Kuno ini ditandai dengan temuan struktur batu bata bangunan identik dengan zaman kerajaan Singosari yang ditemukan pada saat proyek pembangunan Perumahan Taman Tirta (Midaada, 2020). Selanjutnya adalah Situs Pendem yang berada di Desa Pendem, Kota Batu. Situs Pendem ini ditandai dengan tumpukan batu bata kuno berserakan dan juga terpendam di lokasi yang berjarak $1 \mathrm{~km}$ dari perakampungan warga yang ditemukan pada saat warga melakukan aksi protes terhadap pembangunan Wana Wisata Alaska atau Alas Kasinan (Bhirawa, 2020). Begitu juga di Kabupaten Malang, ditemukan sebuah situs sejarah berdasarkan kegiatan pembangunan yaitu Tol Pandaan-Malang di Desa Sekarpuro. Penemuan situs sejarah ini dinamakan sesuai lokasi penemuanya yaitu sebagai Situs Sekaran (Arifin, 2019).

Situs-situs sejarah ini tentu tidak boleh terbengkalai, sehingga perlu dilestarikan, karena merupakan kekayaan bangsa. Hal ini karena merupakan kekayaan bangsa yang perlu dijaga sebagai identitas bangsa (Nurcahyo , 2011). Meskipun demikian, pada kenyataannya masih saja ditemukan beberapa situs sejarah yang terbengkalai. Hal ini tidak menutup kemungkinan situs sejarah akan hilang dan punah akibat tidak adanya upaya penanganan secara serius. Oleh karena itu pelestarian perlu dilakukan dengan sangat serius melalui sinergi antara masyarakat sekitar, pemerintah, dan pemerhati sejarah.

Peran antara masyarakat dan pemerintah sangat vital dalam melindungi situs sejarah ini agar tidak terbengkalai (Fatimah, 2014). Upaya masyarakat dalam pelestarian situs sejarah sangat dibutuhkan untuk menjaga dan melindungi kebudayaan bangsa. Jika situs sejarah tidak dijaga dan dilestarikan, generasi berikutnya akan lupa dengan kebudayaan bangsa yang kita miliki seiring dengan perkembangan zaman. Selanjutnya, 
jika kita tidak menjaga dan melestarikan situs sejarah, hasil kebudayaan kita bisa-bisa akan dikaji oleh orang lain, dimiliki oleh orang lain, dan lama-lama akan menghilang. Maka hal ini dapat menyebabkan identitas dari kebudayaan bangsa Indonesia juga akan hilang.

Tujuan penelitian ini adalah untuk menganalisis pelestarian Situs Cagar Budaya Sekaran di Desa Sekarpuro Kecamatan Pakis Kabupaten Malang. Adapun hal tersebut dapat diketahui dari proses penemuan Situs Sekaran, peran pemerintah desa dalam pelestarian Situs Sekaran, dan peran arkeolog, sejarawan, BPCB (Balai Pelestarian Cagar Budaya) dan komunitas peduli sejarah dalam pelestarian Situs Sekaran di Desa Sekarpuro Kecamatan Pakis Kabupaten Malang. Dari paparan di atas, maka peneliti tertarik untuk mengkaji tentang "Analisis Pelestarian Situs Cagar Budaya Sekaran (Study Kasus Situs Sekaran di Desa Sekarpuro Kabupaten Malang".

\section{METODE}

Penelitian ini menggunakan rancangan penelitian kualitatif dengan jenis penelitian deskriptif. Lokasi yang dijadikan sebagai objek penelitian ini adalah Situs Sekaran yang terletak di Desa Sekarpuro Kecamatan Pakis Kabupaten Malang. Alasan peneliti melakukan penelitian pada lokasi ini dikarenakan situs sejarah yang ditemukan perlu untuk diselamatkan dan dilestarikan keberadaannya. Terkait dengan kajian tersebut penelitian ini bertujuan untuk menganalisis tentang pelestarian Situs
Cagar Budaya Sekaran di Desa Sekarpuro Kecamatan Pakis Kabuapten Malang.

Sumber data dalam penelitian ini terdiri atas data primer dan sekunder. Teknik pengumpulan data dalam penelitian ini menggunakan observasi, wawancara, dan dokumentasi. Wawancara dilakukan dengan informan kunci yaitu Sejarawan, Arkeolog, Balai Pelestarian Cagar Budaya (BPCB), Komunitas Peduli Sejarah Jelajah Jejak Malang (JJM), dan Perangkat Desa Sekarpuro. Selain informan kunci, ada pula informan pendukung diantaranya Tokoh Masyarakat Desa Sekarpuro. Adapun teknik analisis data yang digunakan yaitu model interaktif (Huberman \& Miles, 2012) yang terdiri dari pengumpulan data, reduksi data, penyajian data, dan penarikan kesimpulan.

\section{HASIL DAN PEMBAHASAN \\ Sejarah Penemuan Situs Sekaran di Desa Sekarpuro Kecamatan Pakis Kabupaten Malang}

\section{Penemuan Awal Situs Sekaran}

Situs Sekaran ditemukan melalui adanya proyek pembangunan Jalan Tol Pandaan-Malang. Situs tersebut ditemukan di Desa Sekarpuro, Kecamatan Pakis, Kabupaten Malang oleh pekerja proyek pada tanggal 24 Februari 2019. Penemuan situs-situs sejarah di Indonesia terkadang memiliki cerita yang menarik. Ada yang ditemukan berdasarkan proses pembangunan, ada yang ditemukan berdasarkan mimpi, ditemukan berdasarkan perjalanan atau penelusuran, ditemukan berdasarkan Jurnal IImu Sosial dan Humaniora | 393 
penelitian, ditemukan berdasarkan aktivitas pertanian, ditemukan saat aktivitas industri dan ada juga yang ditemukan saat penambangan pasir.

Penemuan situs sejarah

berdasarkan mimpi juga dapat terjadi. Mimpi dapat menjadi pertimbangan, petunjuk dan tanda-tanda tentang suatu hal (Ariyanto, et al., 2014). Dengan ini tanda ditemukannya sebuah situs berdasarkan mimpi bisa saja terjadi. Hal ini dikuatkan dengan hasil temuan Situs Terung di Desa Terung Wetan, Kecamatan Krian, Sidoarjo. Situs ini ditemukan di salah satu rumah warga setelah menerima isyarat melalui mimpi bahwa tanah miliknya tidak boleh didirikan bangunan. Adapun temuan tersebut adalah batu berbentuk manggis dan dua sumur (Susanto, 2015). Kemudian ada juga situs sejarah yang ditemukan saat perjalanan atau penelusuran yaitu Situs Susunan Batuan Fondasi di Padukuhan Pereng, Sumberharjo, Prambanan, Sleman. Formasi batu yang berjejer itu ditemukan ketika warga melakukan perjalanan ke hutan untuk mencari potensi wisata di Padukuhan Pereng. Lokasi penemuan saat itu masih tertutup rumpun alang-alang. Ketika dibersihkan terlihat batuan yang menyerupai fondasi dengan anjang batuan mencapai 7 meter (Wawan, 2021).

Penemuan situs sejarah berdasarkan penelitian yaitu Situs Gunung Padang di Desa Karyamukti, Kecamatan Cempaka, Kabupaten Cianjur. Situs ini pertama kali ditemukan pada tahun 1914 oleh peneliti Belanda N. J. Krom. Luas area mencapai 3000 meter persegi dengan tinggi 110 meter. Situs terdiri dari teras 1 sampai dengan teras 5 , yang dibatasi oleh batu-batuan (Akbar , 2013). Selanjutnya penemuan situs sejarah berdasarkan aktivitas pertanian yaitu Situs Fondasi Kuno di Desa Sapi Kerep, Kecamatan Sukapura, Kabupaten Probolinggo. Situs tersebut ditemukan masyarakat saat petani sedang menggali lahan di area wisata kebun stroberi. Situs ini berupa fondasi berukuran 1 kali 2 meter (Purwadi, 2021). Tidak hanya itu di Kecamatan Jatirejo, Kabupaten Mojokerto juga ditemukan saat aktivias industri yaitu Situs Kumitir. Situs tersebut pertama kali oleh perajin bata ketika membuat bata merah. Situs ini berupa talud kuno atau tembok penguat tanah yang panjangnya lebih dari 200 meter. Ketebalan tembok yang tersusun oleh bata merah kuno $140 \mathrm{~cm}$ dengan ketinggian lebih dari $120 \mathrm{~cm}$ (Arlado, 2019).

Penemuan situs sejarah pada saat aktivitas penambangan pasir yaitu Situs Kedaton di Dusun Kedaton, Kabupaten Jombang. Situs ini ditemukan saat menggali lahan bekas persawahan. Adapun benda temuan berupa tumpukan batu bata kuno secara struktur membentuk bekas dinding dengan kedalaman $160 \mathrm{~cm}$ dan serpihan tengkorak manusia (Wismabrata, 2019). Selanjutnya penemuan situs sejarah berdasarkan pembangunan yaitu Petirtaan Kuno di Dusun Kebonagung, Desa Brumbung. Situs ini ditemukan saat warga hendak menggali tanah untuk membuat kolam renang anak sebagai fasilitas pendukung wisata. situs tersebut merupakan struktur berbentuk persegi 
empat seluas 5,2 meter persegi dengan panel dan relief khas pada bagian dalam (Sasongko, 2020). Begitu juga di Kabupaten Malang ditemukan sebuah Situs Sejarah berdasarkan proyek pembangunan Jalan Tol di Desa Sekarpuro, Kecamatan Pakis. Situs ini pertama kali ditemukan para pekerja Tol Malang-Pandaan saat mengerjakan ruas tol seksi 5 di KM 37. Sebagian dari bangunan situs berupa struktur batu bata kuno ini sudah rusak terkena kerukan alat berat proyek tol saat menggali tanah (Midaada, 2019).

Jalan Tol merupakan fasilitas umum yang strategis dan merupakan salah satu prasarana transportasi darat yang memegang peranan penting dalam kehidupan manusia (Fitriana, 2014). Jalan Tol yang posisinya jauh dari pemukiman mungkinkan untuk pembukaan lahan baru. Salah satu faktor yang mempengaruhi perubahan tata guna lahan adalah transportasi (Masykuroh \& Rudiarto, 2016). Lahan baru juga terkadang menyimpan suatu sumber daya tertentu berupa temuan sumber daya alam atau hal-hal tertentu. Lahan baru terkadang juga menyimpan nilai budaya atau warisan budaya (Adman, et al., 2018). Sehingga pembangunan Jalan Tol ini memang terkadang membuka hal-hal yang baru.

Situs Sekaran dikenal masyarakat Desa Sekarpuro pada jaman dahulu sebagai struktur bata-bata kuno, namun masyarakat tidak mengetahui bahwa bata-bata kuno tersebut merupakan situs sejarah dan tidak pernah melaporkannya. Masyarakat Desa Sekarpuro menggunakan bata-bata kuno tersebut untuk campuran bahan membuat semen, untuk mendirikan bangunan dan dijadikan pondasi rumah karena kesadaran sejarah yang rendah. Hal ini dapat dibuktikan dengan lulusan jenjang pendidikan SD (Sekolah Dasar) menjadi golongan yang paling besar pada masyarakat Desa Sekarpuro. Kesadaran sejarah merupakan sesuatu yang penting dimiliki setiap masyarakat. Kesadaran sejarah dapat menjadikan masyarakat sebagai makhluk yang berperadaban yaitu berkembang atau maju (Amin, 2018). Oleh karena itu untuk mencapai tujuan pelestarian Situs Sekaran diperlukan kesadaran sejarah pada setiap masyarakat untuk memajukan kebudayaan nasional (Amboro, 2015). Pendidikan dan kesadaran masyarakat menjadi kunci utama upaya pelestarian situs sejarah sebagai kebudayaan bangsa (Yulianto, 2019).

\section{Pemugaran Situs Sekaran}

Penemuan Situs Sekaran pada proyek Jalan Tol Pandaan-Malang menyebabkan beberapa opsi muncul agar tetap terselamatkan. Beberapa opsi penyelamatan diantaranya yaitu pembuatan jalan layang, jalan tol digeser ke sebelah barat, dan jalan tol diseger ke sebelah timur. Penyelamatan situs ini tidak terlepas dari kontribusi berbagai pihak yang berjasa yaitu Ikatan Ahli Arkeolog Indonesia (IAAI) Komda Jawa Timur, Balai Pelestarian Cagar Budaya (BPCB) Jawa Timur, pers, pengelola Jalan Tol yaitu Jasa Marga, komunitas peduli sejarah yaitu Jelajah Jejak Malang (JJM) dan masyarakat sekitar.

Opsi penyelamatan Situs Sekaran memiliki hasil akhir dengan pilihan menggeser arah jalan tol ke timur

Jurnal IImu Sosial dan Humaniora | 395 
hingga 17,5 meter dari titik semula. Penggeseran ini dilakukan oleh pengelola jalan tol sebagai upaya penyelamatan Situs Sekaran. Sejalan dengan Mailina (2017) bahwa peninggalan sejarah harus diselamatkan karena memiliki nilai dan manfaat yang tinggi. Pengambilan opsi untuk mengalihkan proses pembangunan ini sering dilakukan karena merupakan jalan terbaik setelah dilakukan berbagai macam cara diskusi atau rapat. Sebagaimana ini dilakukan juga di Situs Makam Ulama dan Umara Kerajaan Aceh Darussalam di kawasan Istana Darul Makmur, Gampong Pande, Banda Aceh. Dimana pembangunan Jalan Tol Sigli-Banda Aceh menyebabkan Majelis Permusyawaratan Ulama (MPU) Aceh menerbitkan fatwa tentang penyelamatan serta tidak menggusur situs sejarah dan Cagar Budaya (Hendri, 2021). Namun ada juga situs sejarah yang harus terpaksa tertimbun akibat dari adanya proses pembangungan. Sebagai contoh Situs Cagar Budaya Rumah Panggung sebanyak 18 unit di Kota Balikpapan. Situs ini tertimbun karena adanya pembangunan apartemen PT Pertamina yang menjadi salah satu agenda pengembangan kilang minyak Balikpapan (Handoko D. T., 2016). Tidak dapat dipungkiri bahwa keadaan yang terjadi sekarang, kepentingan benda-benda bersejarah dalam pembangunan daerah sudah dikesampingkan demi pembangunan dan tidak memikirkan nilai-nilai sejarah yang akan punah (Tuppang, 2019).

Cagar Budaya memiliki sifat rapuh, unik, langka, terbatas, tidak terbarui sehingga harus dilindungi dan diselamatkan keberadaannya (Nurhalimah, 2019). Hal ini sesuai dengan temuan penelitian, Situs Sekaran tetap bisa terselamatkan walaupun berada pada proses pembangunan yaitu Tol PandaanMalang. Berdasarkan Siaran Pers nomor: $\quad$ 087/Sipres/A5.3/HM/III/2019 menerangkan bahwa pada 5 Maret 2019 kepala Balai Pelestarian Cagar Budaya (BPCB) Jawa Timur menindaklanjuti Situs Sekaran dengan memerintahkan Juru Pelihara wilayah Malang untuk mengamankan temuan tersebut. Kemudian pada 6 Maret 2019 tim unit Penyelamatan dan Pengamanan Balai Pelestarian Cagar Budaya (BPCB) Jawa Timur melakukan tindak lanjut pada lokasi temuan.

Situs sejarah yang baru saja ditemukan harus dilindungi dan diselamatkan keberadaannya melalui proses pemugaran. Pemugaran bertujuan untuk menyelamatkan dan memelihara warisan budaya bangsa (Kusmiati, et, al., 1982a). Pemugaran perlu dilakukan melalui sebuah metode ekskavasi arkeologi. Metode ekskavasi arkeologi merupakan sebuah metode untuk mendapatkan data arkeologi, dengan menggali atau mengekskavasi tempat-tempat yang memiliki indikasi bahwa di dalam tanah tersimpan benda-benda arkeologi baik di dibawah tanah maupun di bawah air (Suantika, 2012). Adapun tujuan dari eskavasi adalah mengumpulkan data arkeologi yang awalnya terpendam dibawah tanah menjadi terkenali dan dapat di identifikasi (Maharoesman, et, al., 2013). Lebih lanjut Suantika (2012) menjelaskan bahwa kegiatan ekskavasi 
arkeologi ini terdiri atas beberapa jenis yaitu ekskavasi atau penggalian percobaan (trial excavation), ekskavasi pelatihan (training excavation), ekskavasi penyelamatan (rescue excavation) dan ekskavasi total (total excavation). Pemugaran yang dilakukan di Situs Sekaran pada tahun 2019 berupa ekskavasi penyelamatan (rescue excavation). Hal ini sesuai dengan kegiatan ekskavasi pada situs ini dilaksanakan dengan tujuan untuk menyelamatkan tinggalan-tinggalan arkeologi yang ditemukan di suatu tempat secara tidak sengaja yaitu saat proses pembangunan Jalan Tol. Jika tidak dipugar maka akan menghilang, padahal ini adalah hal yang penting. Hal ini sesuai dengan laporan pemugaran Kusmiati, et al. (1982b) untuk melakukan pemugaran situs sejarah harus dilakukan pembongkaran dan pengembalian ke tempat semula untuk memperpanjang umur suatu bata agar tidak runtuh.

Pemugaran berupa ekskavasi penyelamatan (rescue excavation) ini juga pernah dilakukan pada Situs Indihiang di Kota Tasikmalaya yaitu untuk menemukan dan menggambarkan bentuk arsitektur Hindu-Buddha di wilayah Tatar Sunda (Widyastuti, 2017). Kemudian juga pada Situs Karang Bui di perairan pantai utara Jawa Barat yang melakukan ekskavasi penyelamatan dikarenakan jumlah artefak semakin berkurang sebagai akibat dari penjarahan dan faktor sedimentasi (Gemilang, et al., 2020). Selanjutnya Situs Masjid Kauman-Pleret di Kabupaten Bantul yaitu dilakukan untuk mencari susunan lantai dan struktur dinding bangunan masjid (Sulistyanto, 2016). Selain itu Situs Babadan di Kabupaten Kediri yang dilakukan dengan tujuan untuk mencari informasi keberadaan dan mengetahui kondisi objek arkeologis guna reinventarisasi (Budiono, et al., 2018). Tidak hanya itu ekskavasi penyelamatan juga dilakukan pada Situs Cot Sidi Abdullah di Kabupaten Aceh Utara untuk memetakan situs berdasarlan model resistivitas guna mencegah kerusakan pada situs arkeologi (Pramana, et al., 2018). Begitu juga di Kabupeten Malang dilakukan ekskavasi penyelamatan pada temuan Situs Sekaran selama sepuluh hari. Ekskavasi Situs Sekaran terdiri dari dua tahap. Ekskavasi tahap I tanggal 12-16 Maret 2019 dan ekskavasi tahap II tanggal 17-27 Maret 2019. Ekskavasi penyelamatan ini melibatkan publik seperti komunitas peduli, perorangan, dan institusi kampus. Sejalan dengan penuturan Susanti (2016) secara arkeologi setiap Cagar Budaya erat kaitannya dengan lingkungan umum dan budayanya. Oleh karena itu perlindungan Cagar Budaya harus mencakup perlindungan Cagar Budaya itu sendiri dan lingkungannya.

Kegiatan ekskavasi penyelamatan ini melibatkan warga Desa Sekarpuro dengan tujuan membantu hal-hal tertentu yang bisa dilakukan oleh khalayak umum, tentunya bukan hal-hal yang membutuhkan persyaratan teknis. Masyarakat lokal dapat membantu proses ekskavasi yang dilakukan bersama dengan orang-orang yang mempelajari kebudayaan masa lalu melalui kajian terhadap benda-benda yang ditemukan dari alam (Aji, et al., 
2021). Oleh karena itu masyarakat Desa Sekarpuro dapat terlibat dalam pemagaran, mengupas tanah, dan kerja bakti saat proses ekskavasi Situ Sekaran. Hal ini senada dengan Soekanto, et al. (1993) pembersihan situs dilakukan secara mekanis dengan menggunakan peralatan sesuai keperluannya dan dilakukan dengan hati-hati mengingat pentingnya peninggalan tersebut. Langkah selanjutnya setelah ekskavasi penyelamatan yaitu dilakukan kegiatan mencegah lupa dan peduli Situs Sekaran yang dilaksanakan oleh masyarakat seni dan budaya Malang raya. Kegiatan ini bertujuan menarik simpati masyarakat dan pemerintah untuk penanganan selanjutnya.

Menurut Riski (2014) perlu diambil langkah-langkah bijak untuk mengantisipasi permasalahan yang ada tanpa merugikan masyarakat yang sudah berada di kawasan situs sejarah. Situs Sekaran perlu dilestarikan dan dilakukan langkah-langkah bijak dalam mengantisipasi permasalahan yang ada. Dengan demikian pada tahun 2020 diadakan acara syukuran menjelang tindak lanjut yang dilakukan untuk pelestarian Situs Sekaran. Adapun tujuan dari syukuran yaitu memohon pada Tuhan Yang Maha Esa agar diberikan hasil yang baik dan dihindarkan dari mara bahaya (Alimaturriyah \& Prasojo, 2020). Syukuran tersebut dilaksanakan sebelum pembangunan atap untuk penyelamatan Situs Sekaran secara bersama yang dihadiri oleh Bupati Kabupaten Malang dan berbagai pihak yang terlibat dalam pelestarian Situs Sekaran. Hal ini sejalan dengan penelitian Nurcahyo (2011) bahwa peninggalan sejarah berupa situs sejarah harus diamankan dan dijaga temuannya, karena merupakan kekayaan bangsa yang perlu dijaga sebagai identitas bangsa.

\section{Peran Pemerintah Desa Dalam Pelestarian Situs Sekaran di Desa Sekarpuro Kecamatan Pakis Kabupaten Malang}

Sesuai dengan Undang-Undang Cagar Budaya Nomor 11 Tahun 2010, pelestarian Situs Sekaran memerlukan sinergi antar elemen yang ada di pemerintah dan masyarakat. Sayangnya, dapat dikatakan bahwa Pemerintah Kabupaten Malang kurang memperhatikan hal tersebut dan kurang memperhatikan temuan situs yang ada saat ini. Belum adanya lembaga pemerintahan tingkat kabupaten yang berwenang dalam pelestarian Cagar Budaya menjadi penghambat dalam proses pelestarian Situs Sekaran. Hal ini sesuai dengan penelitian Pratikno, et al. (2020) yaitu pemerintah dalam hal Kementrian Pendidikan dan Kebudayaan perlu membentuk unit pelaksana teknis yang memiliki tugas dan fungsi khusus dalam pelestarian Cagar Budaya yaitu Balai Pelestarian Cagar Budaya.

Kebijkan peran pemerintah desa dalam pelestarian Situs Sekaran terdiri dari perawatan, perlindungan, dan pengawasan. Sejalan dengan penelitian Abdillah (2020) bahwa peran pemerintah desa setempat dalam pelestarian situs sejarah dapat dilakukan dengan melakukan upaya dalam menjaga dan memelihara situs tersebut. Dengan demikian bentuk dari 
peran pemerintah desa dalam pelestarian Situs Sekaran berupa penyelamatan awal.

Bentuk perawatan yang sudah dilakukan pada Situs Sekaran berupa kerja bakti dan penanaman bunga pada sekitar Situs Sekaran. Hal ini senada dengan penelitian Khakim, et al. (2020) bahwa perawatan situs sejarah dapat dilaksanakan dengan membersihkan rumput dan sampah di sekitar area situs. Selanjutnya perlindungan yang sudah dilakukan pada Situs Sekaran berupa pembuatan pagar bambu. Sesuai dengan penelitian Wuryani \& Purwiyastuti (2012) perlindungan dapat dilakukan dengan pemberian pagar pelindung untuk peninggalan sejarah. Dan pengawasan yang telah dilaksanakan pemerintah desa berupa pengawasan agar tidak ada masyarakat yang mengambil bendabenda temuan di Situs Sekaran. Sejalan dengan penelitian Adiwijawa (2011) bahwa pengawasan situs dapat berupa menjaga keamanan situs dari pengunjung.

Peran pemerintah desa dalam penyelamatan awal Situs Sekaran bersifat formal yaitu hanya sebatas penanganan awal bersama akademisi berserta instansi yang terlibat. Hal ini sesuai dengan penelitian Edo (2017) bahwa upaya penyelamatan dilakukan oleh lembaga penelitian, masyarakat akademis, dan instansi yang terlibat dalam penyelamatan situs sejarah tersebut.

Peran arkeolog, sejarawan, ВРСВ (Balai Pelestarian Cagar Budaya) dan komunitas peduli sejarah Dalam Pelestarian Situs Sekaran di Desa

\section{Sekarpuro Kecamatan Pakis Kabupaten Malang}

Peran arkeolog, sejarawan, BPCB (Balai Pelestarian Cagar Budaya) dan komunitas peduli sejarah sangat penting untuk mendorong pelestarian Situs Sekaran di Desa Sekarpuro. Peran pemerhati sejarah dalam pelestarian Situs Sekaran di Desa Sekapuro Kecamatan Pakis Kabupaten Malang terdiri dari penyelamatan sejak situs ditemukan, pengawalan rapat, pemugaran, mendorong pelaksanan riset, dan menetapkan situs sebagai Cagar Budaya berdasarkan wilayah administratif.

Bentuk dari peran arkeolog adalah menyuarakan temuan Situs Sekaran menggunakan saluran Asosiasi Ahli Arkeologi Indonesia (IAAI) untuk menyuarakan tentang temuan yang ada. Sejalan dengan Mansyur (2007) bahwa balai arkeologi bertugas sebagai unit pelaksana tugas pusat penelitian dan pengembangan arkeologi nasional yang ditempatkan di daerah. Selain itu keterlibatan arkeolog tentunya juga didasarkan pada tugas yang diembannya yaitu melakukan analisa terhadap benda dan temuan situs sejarah (Mansyur, 2008). Dapat diketahui bahwa arkeolog yang terlibat sejak awal temuan Situs Sekaran adalah Ikatan Ahli Arkeologi Indonesia (IAAI) komda Jawa Timur sesuai dengan lokasi temuan.

Bentuk dari peran sejarawan terlibat dalam pelestarian Situs Sekaran adalah melakukan dorongan untuk penyelamatan Situs Sekaran. Dalam hal ini sejarawan sebagai akademisi yang mempelajari peristiwa di masa lampau. Sesuai dengan penelitian 
Dianingrum (2018) yaitu sejarawan berperan sebagai informan untuk menyampaikan informasi seputar peristiwa sejarah di masa lampau. Peran sejarawan sangat penting dalam meneliti sejarah, menginterpretasikan fakta sehingga bisa dimengerti orang lain (Nurpratiwi \& Putranto, 2017).

$$
\text { Bentuk dari peran Balai }
$$

Pelestarian Cagar Budaya (BPCB) dalam pelestarian Situs Sekaran adalah menetapkan situs sejarah sebagai Cagar Budaya. Namun, belum adanya Balai Pelestarian Cagar Budaya (BPCB) tingkat Kabupaten Malang menjadikan Situs Sekaran belum dilindungi dan dikelola secara maksimal oleh daerah. Sejalan dengan penelitian Mabrun (2012) bahwa faktor yang dapat menghambat perlindungan dan pengelolaan Situs Cagar Budaya adalah pembagian kewenangan antara pemerintah pusat dan pemerintah daerah masih belum jelas, minimnya sumber daya manusia yang ahli di bidang pengelolaan warisan budaya, belum efektifya lembaga yang berwenang mengurusi, serta regulasi yang belum diatur dan ditegakkan secara jelas.

Bentuk dari peran komunitas peduli sejarah dalam pelestarian Situs Sekaran adalah melakukan pelaporan tinjauan awal dan penyelenggara acara kesenian. Komunitas peduli sejarah yang turut serta dalam pelaporan tinjauan awal Situs Sekaran adalah Komunitas Jelajah Jejak Malang (JJM) yang diketuai oleh Bapak Restu Restapati. Sejalan dengan Siaran Pers (Nomor: $087 /$ Sipers/A5.3/HM/III/2019) bahwa Kementrian Pendidikan dan Kebudayaan (Kemendikbud) melalui
Balai Pelestarian Cagar Budaya (BPCB) Provinsi Jawa Timur menerima laporan dari masyarakat, atas nama Retu Restapati mengenai ditemukannya bata kuno di Desa Sekarpuro, Kecamatan Pakis, Kabupaten Malang. Kemudian sebagai bentuk upaya pelestarian Situs Sekaran, komunitas Jelajah Jejak Malang (JJM) juga menyelenggrakan acara kesenian yang dilaksanakan setelah pemugaran berupa ekskavasi penyelamatan. Hal ini sesuai dengan penelitian Hamzah (2017) bahwa tujuan terbentuknya komunitas peduli sejarah adalah untuk menjaga dan melestarikan peninggalan bersejarah. Sejalan dengan penuturan Ransnawi (2020) bahwa latar belakang berdirinya komunitas peduli sejarah dipengaruhi oleh kondisi Cagar Budaya dan ketidaksiapan pemerintah dalam merancang peraturan daerah tentang perlindungan Cagar Budaya.

Sifat arkeolog, sejarawan, BPCB (Balai Pelestarian Cagar Budaya) dan komunitas peduli sejarah dalam pelestarian Situs Sekaran di Desa Sekarpuro, Kecamatan Pakis, Kabupaten Malang saling berdampingan dengan pemerintah Kabupaten Malang. Pelestarian Situs Sekaran bisa terlaksana dengan baik apabila pemerintah Kabupaten Malang dapat menetapkan langkah-langkah bijak dalam pelestarian Situs Sekaran kedepannya.

\section{SIMPULAN DAN SARAN}

Situs Sekaran ditemukan tanggal 24 Februari 2019 pada saat penggalian tanah yang dilakukan oleh pekerja proyek tol Malang-Pandaan di Desa

Jurnal IImu Sosial dan Humaniora | 400 
Sekarpuro, Kecamatan Pakis, Kabupaten Malang. Pemugaran yang dilakukan pada Situs Sekaran berupa ekskavasi penyelamatan (rescue excavation) pada tahun 2019 serta penyediaan dinding penahan dan atap pelindung baja pada tahun 2020. Peran pemerintah desa dalam pelestarian Situs Sekaran berupa penyelamat awal yaitu perawatan, perlindungan dan pengawasan. Peran arkeolog, sejarawan, BPCB (Balai Pelestarian Cagar Budaya) dan komunitas peduli sejarah dalam pelestarian Situs Sekaran meliputi penyelamatan sejak ditemukannya situs tersebut, pemugaran, mendorong penelitian dan menetapkannya sebagai Cagar Budaya menurut wilayah administratifnya. Penelitian selanjutnya disarankan untuk mengkaji tentang kesadaran sejarah masyarakat dalam pelestarian situs sejarah.

\section{DAFTAR PUSTAKA}

Abdillah, J. (2020). Analisis Peran Partisipasi Masyarakat dan Pemerintah Desa Dalam Upaya Pengelolaan dan Pelestraian Cagar Budaya di Desa Kota Kapur Kecamatan Mendo Barat Kabupaten Bangka. Doctrinal, 5(2), 187-191.

Adiwijaya, R. (2011). Upaya Pemeliharaan Benda Cagar Budaya dan Peninggalan Sejarah Menurut Data Balai Arkeologi Kepurbakalaan, Sejarah dan Nilai Tradisional. disesertation: Universitas Widyatama.

Adman, B., Mukhlisi, Muslimin, T., Arifin, Z., Priyono, Rengku, M. T.,
Ningsih, M. K. (2018). Kawasan

Wana Parta Letari Gunung Sepuluh Timur PT Pertamina RU $V$. Balikpapan: PT. Pertamina RU $\checkmark$ Balikpapan.

Afida, R., Basuki, A., \& Turaeni, N. (2014). Virtual Tour Situs Sejarah Candi Jago Kabupaten Malang Berbasis Android. Jurnal Informatika dan Komputer PENS, 1(1).

Aji, I. S., Cikusin, Y., \& Abidin, A. Z. (2021). Pelestarian Cagar Budaya Situs Baru Kumitir Berbentuk Talud Kerajaan Majapahit (Studi Kasus Desa Kumitir, Kecamatan Jatirejo, Kabupaten Mojokerto). Respon Publik, 15(2), 1-5.

Akbar, A. (2013). Situs Gunung Padang Misteri dan Arkeologi. Jakarta Selatan: Change.

Alimaturriyah, \& Prasojo, Z. H. (2020). Interaksi Islam dan Budaya Lokal Dalam Tradisi Syukuran Laut di Kuala Jelai Kalimantan Tengah. Jurnal Kajian Islam dan Pendidikan Tadarus Tarbawy, 2(1).

Amboro, K. (2015). Membangun Kesadaran Berawal Dari Pemahaman; Relasi Pemahaman Sejarah dengan Kesadaran Sejarah Mahasiswa Program Studi Pendidikan Sejarah Fkip Universitas Muhammadiyah Metro. HISTORIA: Jurnal Program Studi Pendidikan Sejarah, 3(2), 109-118.

Amin, M. (2018). Kedudukan Akal dalam Islam . Tarbawi: Jurnal Pendidikan Agama Islam, 3(01), 79-92.

Jurnal IImu Sosial dan Humaniora | 401 
Arifin, Z. (2019). Melacak Umur Situs Sekaran Peninggalan PraMajapahit di Tol Malang. Malang: Liputan6.com.

Dari https://www.liputan6.com/regional /read/3939639/melacak-umursitus-sekaran-peninggalan-pramajapahit-di-tol-malang.

Ariyanto, A., Rachman, I., \& Toknok, B. (2014). Kearifan Masyarakat Lokal Dalam Pengelolaan Hutan di Desa Rano Kecamatan Balaesang Tanjung Kabupaten Donggala. Jurnal Warta Rimba, 2(2).

Arlado, I. (2019). Ganti Rugi Lahan Situs Dikeluhkan. Mojokerto: radarmojokerto.jawapos.com.

Dari

https://radarmojokerto.jawapos.co $\mathrm{m} / \mathrm{read} / 2019 / 11 / 01 / 163907 / g a n t i-$ rugi-lahan-situs-dikeluhkan.

Bhirawa, D. (2020). Satu Lagi Tempat Diduga Situs Sejarah Ditemukan di Kota Batu. Batu: Bhirawa Oline.

Dari https://www.harianbhirawa.co.id/s atu-lagi-tempat-diduga-situssejarah-ditemukan-di-kota-batu/.

Budiono, H., Widiatmoko, S., Budianto, A., \& Afandi, Z. (2018). Inventaris Cagar Budaya Kevamatan Badas, Ngampeng Rejo, Ngrogol dan Gurah Kabupaten Kediri. Jurnal ABDINUS: Jurnal Pengabdian Nusantara, 1(2), 126-132.

Dianingrum, I. (2018). Studi Historiografi: Sejarah Lanud Sulaiman Karya Jokoo Nugroho. Bandung: Doctoral dissertation, UIN Sunan Gunung Djati Bandung.
Edo , R. (2017). Situs Pancur Gading Putri Hijau Kondisi dan Permasalahannya. Medan: Doctoral dissertation, Universitas Negeri Medan.

Fatimah, T. (2014). Gion Matsuri: Prosesi Budaya, Partisipasi Komunitas dan Pelestarian Wajah Kota Kyoto. NALARs, 13(1).

Firmansyah, D., \& Soesilo, F. (2020). Sejarah Daerah Malang Timur, Mengenal Toponimi dan Sejarah Lokal Desa-Desa di Derah Pakis dan Sekitarnya. Malang: Intelegensia Media.

Fitriana, R. (2014). Studi Komparasi Perencanaan Tebal Perkerasan Kaku Jalan Tol Menggunakan Metode Bina Marga 2002 Dan AASHTO 1992 (Studi Kasus: Ruas Jalan Tol Solo-Kertosono). Surakarta: Universitas Muhammadiyah Surakarta.

Gemilang, W. A., Ridwan, N. H., Wisha, U. J., Rahmawan, G. A., Ilham, \& Tahir, Z. (2020). Kerentanan Tinggalan Budaya Bawah Air Situs Karang Bui di Perairan Pantai Utara Jawa Barat. AMERTA, Jurnal Penelitian dan Pengembangan Arkeologi.

Hamzah, S. (2017). Peranan Sultan Muhammad Salahuddin dalam Perkembangan Islam di Bima. Makasar: Doctoral dissertation, Universitas Islam Negeri Alauddin Makasar.

Handoko, D. T. (2016). Gusur Rumah Panggung, Proyek Apartemen Digugat. Balikpapan: nasional.tempo.co. Dari https://nasional.tempo.co/read/81 8576/gusur-rumah-panggung-

Jurnal IImu Sosial dan Humaniora | 402 
proyek-apartemendigugat/full\&view=ok.

Handoko, S. (2018). Pengembangan Media Infografis Untuk Pembelajaran Berbasis Sejarah Daerah Menampilkan Eksistensi Candi Songgoriti di SMK Ardjuna 2 Malang. Semarang: Doctoral dissertation, Universitas Negeri Malang.

Hendri. (2021). MPU Terbitkan Fatwa Penyelamatan Situs Sejarah dan Cagar Budaya, Ini Hukum Menjual dan Merusak Situs. Banda Aceh: aceh.tribunnews.com. Dari https://aceh.tribunnews.com/2021 /02/11/mpu-terbitkan-fatwapenyelamatan-situs-sejarah-dancagar-budaya-ini-hukum-menjualmerusak-situs.

Huberman, M. (2012). Analisis Data Kualitatif. Jakarta: Universitas Indonesia Press.

Jelajah Jejak Malang. (2019). Laporan Tinjauan Awal Situs Sekaran Sebuah Dugaan Korelasi Dengan Wilayah Kuno "Kabalan" Masa Mataram-Majapahit. Malang: Dinas Pariwisata dan Kebudayaan Kabupaten Malang dan Komunitas Jelajah Jejak Malang.

Kencana, D., \& Basid, A. (2015). Aplikasi Metode Geomagnetik Untuk Memetakan Situs Arkeologi Candi Badut Malang Jawa Timur. Jurnal Neutrino: Jurnal Fisika dan Aplikasinya, 103-111.

Khakim, M. L., Ramadhan, D. N., Firman, F. D., \& Putri, Y. S. (2020). Kegiatan Perawatan dan Pengenalan Wisata Situs Sejarah
Pada Zaman Kolonial Makam Dinger Di Desa Tulungrejo Kecamatan Bumiaji Kota Batu. Jurnal Praksis dan Dedikasi (JPDS), 3, 6-10.

Kusmiati, N. T., Retnanigsih, S., Dewi, W. D., Hasibuan, H., Subardini, N. N., Surachmad, \& Wiyarto, S. (1982a). Laporan Pemugaran Peninggalan Sejarah dan Purbakala Bali dan Nusa Tenggara Barat. Jakarta: Direktorat Perlindungan dan Pembinaan Peninggalan Sejarah dan Purbakala.

Kusmiati, T. N., Dewi, D. W., Hadniwati, Subardini, N. N., Surachmad, M. M., Wiyarto, S., \& Retnoningsih, S. (1982b). Laporan Seminar Pemugaran dan Perlindungan Peninggalan Sejarah dan Purbakala. Jakarta: Direktorat Perlindungan dan Pembinaan Peninggalan Sejarah dan Purbakala.

Mabrun , J. (2012). Pelestarian Warisan Budaya Dalam Era Otonomi Daerah Berdasarkan Kajian Perundang-Undangan.

Yogyakarta: Pasca Sarjana Jurusan Arkeologi Fakultas IImu Budaya Universitas Gadjah Mada.

Maharoesman, Z. R., Suwardhi, D., \& Indrajaya, A. (2013). Pembangunan Sistem Informasi Geografis Berbasis WEB untuk Kegiatan Ekskavasi Situs Warisan Budaya Indonesia (Studl Kasus: Komplek Candi Batujaya. Jurnal Konservasi Cagar Budaya Borobudur, 7(2), 35-43.

Jurnal IImu Sosial dan Humaniora | 403 
Mailina, L. (2017). Identifikasi dan Pemanfaatan Potensi Sumber Belajar Berbasis Peninggalan Sejarah di Ambarawa Kabupaten Semarang. Semarang: Doctoral dissertation, Universitas Negeri Semarang.

Mansyur, S. (2007). Sumbangan Penelitian Arkeologi Bagi Pembangunan Daerah Maluku. Kapata Arkeologi, 80-100.

Mansyur, S. (2008). Arkeologi Maritim, Kajian Awal untuk Pengembangan Highlight Penenlitian Balai Arkeologi Ambon. Kapta Arkeologi, 4(7), 114.

Masykuroh, D. K., \& Rudiarto, I. (2016). Kajian Perubahan Penggunaan Lahan dan Harga Lahan di Wilayah Sekitar Pintu Tol Ungaran. TATA LOKA, 18(1).

Midaada, A. (2019). 8 Fakta Situs Kuno di Proyek Tol Malang, nomor 2 berbau mistis. Okezone. Dari Dari https://news.okezone.com/read/2 019/03/22/519/2033515/8-faktasitus-kuno-di-proyek-tol-malangnomor-2-berbau-mistis.

Midaada, A. (2020). Situs Kuno Ditemuan di Malang, Diduga Permukiman Kuno Era Kerajaan Singosari. Malang: Okezone. Dari https://news.okezone.com/read/2 020/10/16/519/2294797/situskuno-ditemukan-di-malangdiduga-permukiman-kuno-erakerajaan-singosari?page $=1$.

Nurcahyo , A. (2011). Museum Trowulan dan Historiografi Majapahit Penguat Identitas Bangsa Agastya . Jurnal Sejarah dan Pembelajarannya, 1(1), 8389.

Nurhalimah. (2019). Keberadaan Balai Pengelola Cagar Budaya (BPCB) Banten dalam Pelestarian Situs Cagar Budaya di Daerah Cibungbulang. CHRONOLOGIA, 1(2), 54-71.

Nurpratiwi, H., \& Putranto, A. (2017). Sejarah dan Fakta Kekinian. Tulungagung: Seminar Sejarah Nasional.

Pramana, A. H., Abdullah, F., Afrizal, T., \& Ismail, N. (2018). Pemetaan Struktur Situs Cot Sidi Abdullah Peninggalan Kerajaan Samudera Pasai Berdasarkan Sebaran Model Resistivitas. Jurnal Geografi.

Pratikno, H., Rahmat, H. K., \& Sumantri, S. H. (2020). Implementasi Cultural Resource Management dalam Mitigasi Bencana pada Cagar Budaya di Indonesia. NUSANTARA: Jurnal IImu Pengetahuan Sosial, 7(2), 427-438.

Purwadi, H. (2021). Warga Tengger Gunung Bromo Temukan Situs Purbakala Diduga Sisa Kerajaan Singosari. Kabupaten Malang: jatim.inews.id. Dari https://jatim.inews.id/berita/warga -tengger-gunung-bromo-temukansitus-purbakala-diduga-sisakerajaan-singosari/1.

Ramli, S., \& Wikantoyoso, R. (2018). Makna Ruang Sebagai Aspek Pelestarian Situs Sumberawan . Local Wisdom: Jurnal IImiah Kajian Kearifan Lokal , 10(1), 3142.

Jurnal IImu Sosial dan Humaniora | 404 
Ransnawi, R. (2020). Pembelajaran Sejarah Pada Lembaga NonFormal: Historical Conciousness Komunitas Masyarakat Peduli Sejarah Aceh. Malang: Universitas Negeri Malang.

Riski, P. (2014). Masyarakat Berperan Penting untuk Penyelamatan Situs Bersejarah dan Benda Cagar Budaya. Ketintang: voaindonesia.com. Dari https://www.voaindonesia.com/a/ masyarakat-berperan-pentinguntuk-penyelamatan-situsbersejarah-dan-benda-cagarbudaya/2440830.html.

Sasongko, A. (2020). BPCB Ekskavasi Situs Petirtaan Kuno di Kediri. Kediri: republika.co.id. Dari https://republika.co.id/berita/qdi2a w313/bpcb-ekskavasi-situspertirtaan-kuno-di-kediri.

Siaran Pers.

(Nomor: 087/Sipres/A5.3/HM/III/2019).

Struktur Bata Diduga Cagar Budaya Ditemukan di Kabupaten Malang. Jakarta: Biro Komunikasi dan Layanan Mayarakat, Kementrian dan Kebudayaan.

Soekanto, Sugiyanti, S., Dewi, P., \& Guntur. (1993). Rencana Induk Taman Purbakala Sriwijaya di Karanganyar Palembang. Jakarta: Proyek Pelestarian/ Pemanfaatan Peninggalan Sejarah dan Purbakala.

Suantika, I. W. (2012). Pengelolaan Sumberdaya Arkeologi. Forum Arkeologi, 25 (1), 185-205.

Sulistyanto, I. (2016). Revitalisasi Situs Masjid Kauman-Pleret Sebagai Upaya Rekonstruksi Kehidupan Religi Pada Zaman Kerajaan
Mataram Islam. Jurnal Teknik Sipil dan Arsitektur, 19(23).

Sulistyo, W. D., Khakim, M., \& Jauhari, N. (2020). Jelajah Situs Air di Malang Raya. Malang: Fakultas Ilmu Sosial, Universitas Negeri Malang.

Sulistyo, W., Nafi'ah, U., Agung, D., \& Cahyono, M. (2020). Jejak Sejarah Malang Raya. Malang: CV. Bintang Sejahtera.

Susanti, D. (2016). Strategi Konservasi Berbasis Masyarakat Pada Kompleks Gua Prasejarah Bellae Kabupaten Pangkep, Provinsi Sulawesi Selatan. Yogyakarta: Doctoral dissertation, Universitas Gadjah Mada.

Susanto, A. (2015). Situs Majapahit di Sidoarjo: Pemilik Mimpi Tanahnya Tak Boleh Didirikan Bangunan. Sidoarjo: Solopos.com. Dari https://www.solopos.com/situsmajapahit-di-sidoarjo-pemilikmimpi-tanahnya-tak-bolehdidirikan-bangunan-612770.

Tuppang, K. B. (2019). Perlindungan Hukum Terhadap Hak Cipta Benda-Benda Bersejarah Menurut Undang-Undang Noor 11 Tahun 2010 Tentang Cagar Budaya. Lex Et Societatis, 7(7).

Turaeni, N. (2015). Aplikasi Adi Parwa dalam Relief Situs Candi Kidal. In Forum Arkeologi, 28(2), 131-144.

Wawan, J. H. (2021). Batu Susun Berjejer Diduga Situs Kuno Ditemukan di Prambanan. Magelang: news.detik.com. Dari https://news.detik.com/beritajawa-tengah/d-5435920/batu-

Jurnal IImu Sosial dan Humaniora | 405 
susun-berjejer-diduga-situs-kunoditemukan-di-prambanan.

Widyastuti, E. (2017). Arsitektur Bangunan Suci di Situs Indihiang Kota Tasikmalaya. Balai Arkeologi Jawa Barat.

Wismabrata, M. H. (2019). 5 Fakta Penemuan Situs Kuno di Jombang, Diduga Bekas Dinding hingga Ada Serpihan Tengkorak Manusia. Kompas.com. Dari https://regional.kompas.com/read/ 2019/06/28/16330161/5-faktapenemuan-situs-kuno-dijombang-diduga-bekas-dindinghingga-ada?page=all.

Wuryani, E., \& Purwiyastuti, W. (2012). Menumbuhkan Peran Serta Masyarakat Dalam Melestarikan Kebudayaan dan Benda Cagar Budaya Melalui Pemberdayaan Masyarakat Di Kawasan Wisata Dusun Ceto. Satya Widya, 28(2), 147-154.

Yulianto. (2019). Pelestarian Situs dan Benda Bersejarah Harus Libatkan Komunitas Pecinta Budaya. Boyolali: FokusJateng.com. Dari https://www.fokusjateng.com/201 9/11/20/pelestarian-situs-danbenda-bersejarah-harus-libatkankomunitas-pecinta-budaya/.

Zahroh, N. (2014). Pemanfaatan Situs Singosari dalam Mengembangkan Literasi Sejarah Peserta Didik. J-PIPS, 1(1), 159. 